\title{
PETA ZONASI TSUNAMI INDONESIA
}

\author{
Theodore F. Najoan ${ }^{[1]}$, Ari Budiman ${ }^{[2]}$
}

\begin{abstract}
ABSTRAK
Kepulauan Indonesia berada pada daerah rawan gempa, dengan resiko gempa yang dapat menyebabkan tsunami dapat terjadi pada berbagai tempat di setiap pulau. Gempa bumi yang menyebabkan gelombang tsunami dapat menghancurkan kota-kota pada daerah pesisir pantai. Oleh karena itu peta rawan tsunami terus dikembangkan, untuk memberikan informasi mengenai tinggi rayapan tsunami untuk keperluan desain bangunan maupun instansi pemerintah di seluruh kepulauan Indonesia. Peta rawan tsunami berdasarkan kejadian gempa yang menyebabkan tsunami pada suatu wilayah, dan menghitung tinggi rayapan tsunami dengan menggunakan rumus Katyusuki Abe (1995). Peta rawan tsunami dibagi menjadi 5 zona, yaitu zona 0 dengan $\alpha=0,00-0,29$, zona 1 dengan $\alpha=$ $0,30-0,49$, zona 2 dengan $\alpha=0,50-0,69$, zona 3 dengan $\alpha=0,70-0,89$ dan zona 4 dengan $\alpha=$ $0,90-1,10$.
\end{abstract}

Kata Kunci : Tsunami, Tinggi rayapan, Tinggi rayapan maksimum, Tinggi rayapan dasar, Tinggi rayapan dasar maksimum, Peta, Kefisien zona.

\begin{abstract}
Indonesian archipelago is located on a very active seismic zone, in which tsunami earthquake can happen in many location of the island. This tsunami earthquake can destroy city and town on the coast line. This tragedy will destroy and killed thousand peoples in the area. Because of this, a tsunami risk map have been developed, which will inform designers and goverment officials concerning tsunami runups in Indonesia. The tsunami risk map is based on the tsunami earthquake occurrence in the area, and the empirical formula by Katyusuki Abe (1995) for runups. Tsunami risk map was devided into 5 zone, that was zone 0 with $\alpha=0,00-0,29$, zone 1 with $\alpha=0,30-0,49$, zone 2 with $\alpha=0,50-0,69$, zone 3 with $\alpha=0,70-0,89$ and for zone $4, \alpha=0,90-1,10$.
\end{abstract}

Keywords : Tsunami, Runups, Maximum runrups, Base runups, Maximum base runups, Map, Zone coefficient.

\section{PENDAHULUAN}

Indonesia sebagai negara kepulauan adalah kumpulan gugusan pulau yang secara geografis terletak antara $6^{\circ} \mathrm{LU}-11^{\circ} \mathrm{LS}$ dan $95^{\circ} \mathrm{BT}-140^{\circ} \mathrm{BT}$. Indonesia merupakan daerah pertemuan antara tiga lempeng dunia yang aktif yaitu lempeng Eurasia, Pasifik dan HindiaAustralia yang menjadikan kepulauan Indonesia rawan terhadap terjadinya patahan yang dapat menyebabkan gempa bumi tektonik dan dapat diikuti bencana lainnya seperti longsor dan juga tsunami.

Dengan kondisi tersebut, kepulauan Indonesia sangat rawan terhadap terjadinya gempa bumi terutama daerah-daerah yang memiliki probabilitas gempa sangat tinggi baik itu gempa dangkal maupun gempa dalam. Salah satunya adalah gempa bumi dasar laut (submarine 
earthquake) yang diikuti oleh terjadinya gelombang tsunami, yang dapat menyebabkan kehancuran pada kawasan pesisir pantai. Jumlah korban jiwa dan harta benda yang menjadi korban akibat gelombang tsunami adalah alasan bagi kita untuk mempersiapkan langkahlangkah dan antisipasi terhadap gelombang tsunami. Sistem peringatan tsunami dini (tsunami warning system) dan peta zonasi terhadap daerah rawan gempa laut dan tsunami (tsunami zoning map) adalah salah satu upaya untuk mengurangi jumlah korban.

\section{ASPEK TEKTONISME DAN PENGETAHUAN TSUNAMI}

Bumi memiliki jari-jari sekitar $6378 \mathrm{~km}$. Secara umum, Bumi terdiri dari tiga lapisan utama yaitu crust, mantle dan core. Crust / Lithosfer adalah lapisan yang paling terluar dari bumi berbentuk padat dengan ketebalan lapisan mencapai $100 \mathrm{~km}$. Lithosfer terdiri dari lapisan sima dan lapisan sial. Lapisan sima tersusun dari silisium dan magnesium dengan massa jenis $3.6 \mathrm{gr.cm}^{-3}$, sedangkan lapisan sial tersusun dari silisium dan aluminium dengan

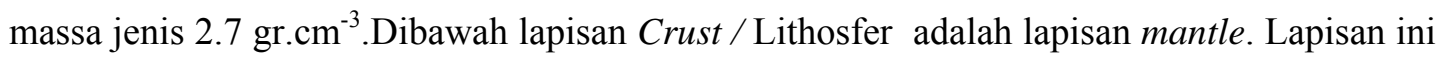
panas yang terdiri dari batuan semi padat yang memiliki ketebalan sekitar $2900 \mathrm{~km}$. lapisan ini terdiri dari banyak besi, magnesium dan kalsium pada lapisan kerak. Lapisan ini memiliki temperatur panas sesuai dengan grafik hubungan antara panas dengan kedalaman yang digambarkan linear. Pada pusat Bumi kita ini terdapat lapisan core yang memiliki ketebalan dua kali lebih tebal dari lapisan mantle. Hal ini disebabkan karena komposisinya yang sangat padat dengan logam, seperti iron, nickel dan alloy. Lapisan ini terpisah menjadi dua bagian. Yang pertama adalah liquid outher core, yang memiliki ketebalan sekitar $2200 \mathrm{~km}$ dan yang kedua adalah solid inner core yang memiliki ketebalan $1250 \mathrm{~km}$. Bersamaan dengan berotasinya bumi, liquid outher core melakukan perputaran juga yang membuat efek magnet Bumi.

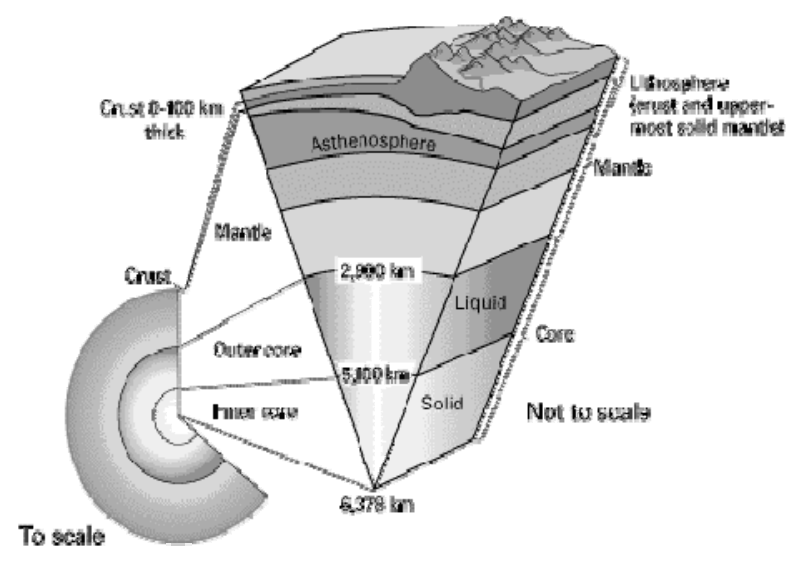

Gambar 1. Struktur Lapisan Penyusun Bumi 


\subsection{Gempa Bumi}

Menurut Aristoteles, gempa bumi mempunyai hubungan erat dengan empat unsur yang membangun bumi, yaitu api, hawa, air dan tanah. Ia menyatakan bahwa hawa yang terkurung di dalam tanah, jika mendapat jalan keluar akan menyebabkan gempa bumi.

Gempa bumi menurut M.T. Zen didefinisikan sebagai gerakan tiba-tiba atau rentetan gerakan tiba-tiba dari tanah dan batuan yang bersifat transient atau sementara dan berasal dari suatu daerah terbatas yang kemudian menyebar ke segala arah karena dirambatkan oleh medium yang ada (lapisan bumi).

Katili (1966) mendefinisikan gempa sebagai suatu sentakan asli yang terjadi di bumi, bersumber dari dalam bumi yang kemudian merambat ke permukaan bumi.

Gelombang tersebut dapat dibedakan atas beberapa jenis :

1. Gelombang Badan (body waves).

2. Gelombang Permukaan (surface waves).

Parameter gempa adalah acuan nilai besaran dan letak kejadian suatu gempa. besaran gempa merupakan suatu ukuran kekuatan yang dihitung berdasarkan data dari alat perekam gempa atau seismograf. Selain itu, parameter gempa harus mampu mempresentasikan letak pusat gempa. Parameter gempa yang memprsentasikan lokasi pusat gempa (hypocenter) dan episentrum (Epicenter). Hiposentrum adalah "titik" dimana energi elastic dilepaskan dalam bentuk gelombang gempa sehingga menimbulkan getaran pada bola bumi. Dengan kata lain, hiposentrum adalah lokasi dari pusat terjadinya gempa.

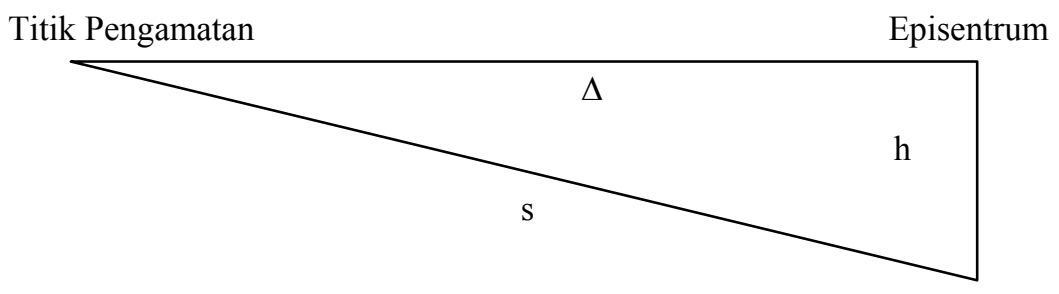

Hiposentrum

Gambar 2. Ilustrasi lokasi Gempa

Model statistik yang paling sederhana untuk menguraikan rangkaian kejadian gempa adalah menggunakan model Guternberg \& Richter (Sudarmono, 1997) dengan penjelasan bahwa frequensi kejadian gempa menurun secara exponensial dengan meningkatnya besaran gempa dan dapat dinyatakan dalam Persamaan 1.

$\log _{10} \mathrm{~N}_{1}(\mathrm{Ms})=\mathrm{a}_{1}-\mathrm{b} \cdot \mathrm{Ms}$ 
Dengan demikian maka frequensi kejadian kumulatif tahunan $\mathrm{N}_{1}(\mathrm{Ms})$ dan perioda ulang $\mathrm{T}$ dapat dinyatakan dengan Persamaan 2 dan Persamaan 3.

$$
\begin{aligned}
& \mathrm{N}_{1}(\mathrm{Ms})=10^{\mathrm{a} 1-\mathrm{b} . \mathrm{Ms}} \\
& T=\frac{1}{N_{1}(M s)}
\end{aligned}
$$

$$
\text { dimana : } \begin{array}{ll}
\mathrm{N}_{1}(\mathrm{Ms}) & =\text { Frekuensi kumulatif dengan besaran } \geq \text { Ms per tahun } \\
\mathrm{a}_{1} & =\text { Konstanta tergantung lamanya pengamatan } \\
\mathrm{b} & =\text { Konstanta tergantung sifat tektonik daerah } \\
\mathrm{T} & =\text { Perioda ulang gempa (tahun) }
\end{array}
$$

Tabel 1. Skala Richter ( Charles Richter, 1935 )

\begin{tabular}{|c|c|}
\hline MAGNITUDE & EXPLANATION \\
\hline 8 & Great Earthquake \\
\hline $7-7.9$ & Major Earthquake \\
\hline $6-6.9$ & Destruktive Earthquake \\
\hline $5-5.9$ & Damaging Earthquake \\
\hline $4-4.9$ & Minor Earthquake \\
\hline $3-3.9$ & Smallest Generaly Felt \\
\hline $2-2.9$ & Some times felt \\
\hline
\end{tabular}

\subsection{Tsunami}

Fenomena tsunami pertama kali dilaporkan terjadi di Jepang. Bahkan istilah tsunami sendiri berasal dari bahasa Jepang. Tsunami berasal dari kata tsu yang berarti pelabuhan, dan nami yang artinya ombak (gelombang air).

Tsunami adalah suatu ombak yang terjadi setelah suatu gempa bumi, gempa laut, gunung berapi meletus, atau hantaman meteor di laut. Tenaga setiap tsunami adalah tetap, fungsi ketinggiannya dan kelajuannya. Dengan itu, apabila gelombang menghampiri pantai, ketinggiannya meningkat sementara kelajuannya menurun.

Tsunami dideskripsikan sebagai suatu gelombang laut dengan perioda panjang yang disebabkan oleh adanya gangguan impulsif yang terjadi di dasar laut. Gangguan impulsif pembangkit tsunami tersebut berasal dari terjadinya deformasi dasar laut secara tiba-tiba. Deformasi dasar laut tersebut diantaranya dapat diakibatkan oleh tiga sumber utama, yaitu :

1. Gempa dasar laut (submarine earthquake), seperti yang terjadi di Alaska tahun 1964.

2. Letusan gunung berapi di dasar laut (submarine eruptione), seperti yang terjadi saat meletusnya gunung krakatau tahun 1883.

3. Longsoran di dasar laut (submarine landslide), seperti yang terjadi di Sagani Bay Jepang tahun 1933. 
Tsunami memiliki karakteristik yang berbeda dengan gelombang pasang (tide wave) atau gelombang permukaan (surface wave) yang biasa dijumpai di pantai. Gelombang pasang disebabkan oleh gaya tarik bulan, sedangkan gelombang permukaan disebabkan oleh gaya seret angin di permukaan laut. Tsunami bersifat transient dan impulsif, artinya semakin melemah dengan bertambahnya waktu dan mempunyai umur sesaat. Hal ini berbeda dengan gelombang permukaan yang bersifat hampir kontinu dan berlangsung dalam waktu yang lama dengan periode gelombang pendek.

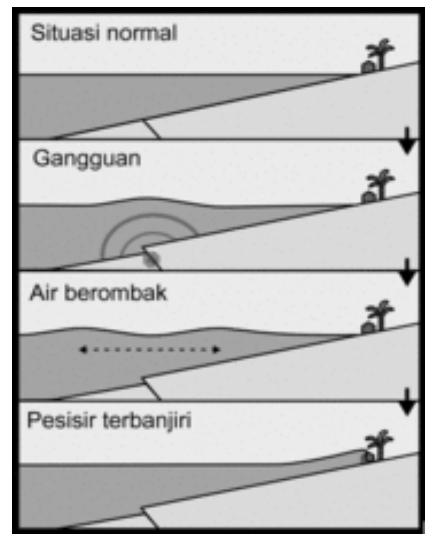

\section{Gambar 3. Skema terjadinya tsunami akibat submarine earthquake}

Tsunami tergolong sebagai jenis gelombang perairan dangkal (shallow water wave) karena mempunyai panjang gelombang 100 - $200 \mathrm{~km}$ yang sangat besar bila dibandingkan dengan kedalaman laut (maksimum $10 \mathrm{~km}$ ). Oleh karena itu kecepatan rambat tsunami sangat bergantung pada kedalaman laut yang dilaluinya. Secara umum dapat dikatakan bahwa kecepatan rambat tsunami akan berkurang dengan berkurangnya kedalaman laut. Kecepatan rambat tsunami di pusatnya pada kedalaman dasar laut sekitar $7000 \mathrm{~m}$ dapat mencapai sekitar $900 \mathrm{~km} / \mathrm{jam}$. Kecepatan rambat tsunami ini akan jauh berkurang pada saat mencapai pantai, yakni menjadi sekitar $50 \mathrm{~km} / \mathrm{jam}$.

Karena terjadi penurunan kecepatan rambat pada saat tsunami merambat di tengah lautan ke pantai, maka akan terjadi penumpukan masa air pada saat tsunami mencapai pantai. Hal ini menyebabkan tinggi gelombang tsunami akan mengalami pembesaran pada saat mencapai pantai. Apabila di tengah lautan tinggi gelobang tsunami sekitar $1-2 \mathrm{~m}$, maka saat mencapai pantai tinggi gelombag tsunami dapat mencapai puluhan meter, dan merayap sampai jauh dari garis pantai. Tinggi gelombang tsunami yang telah sampai ke darat disebut sebagai run-up atau rayapan. 


\section{LANGKAH PEMBUATAN PETA ZONASI TSUNAMI INDONESIA}

Pada penyusunan dan pembuatan peta zonasi tsunami seharusnya memperhatikan beberapa hal lainnya. Antara lain tinggi rayapan dan daerah rendaman, topografi, morfologi pantai dan teknik kelautan. Namun, pada penyusunan peta zonasi tsunami ini, hanya berdasarkan besaran gempa saja. Selain itu peta zonasi ini hanya mewakili local tsunami.

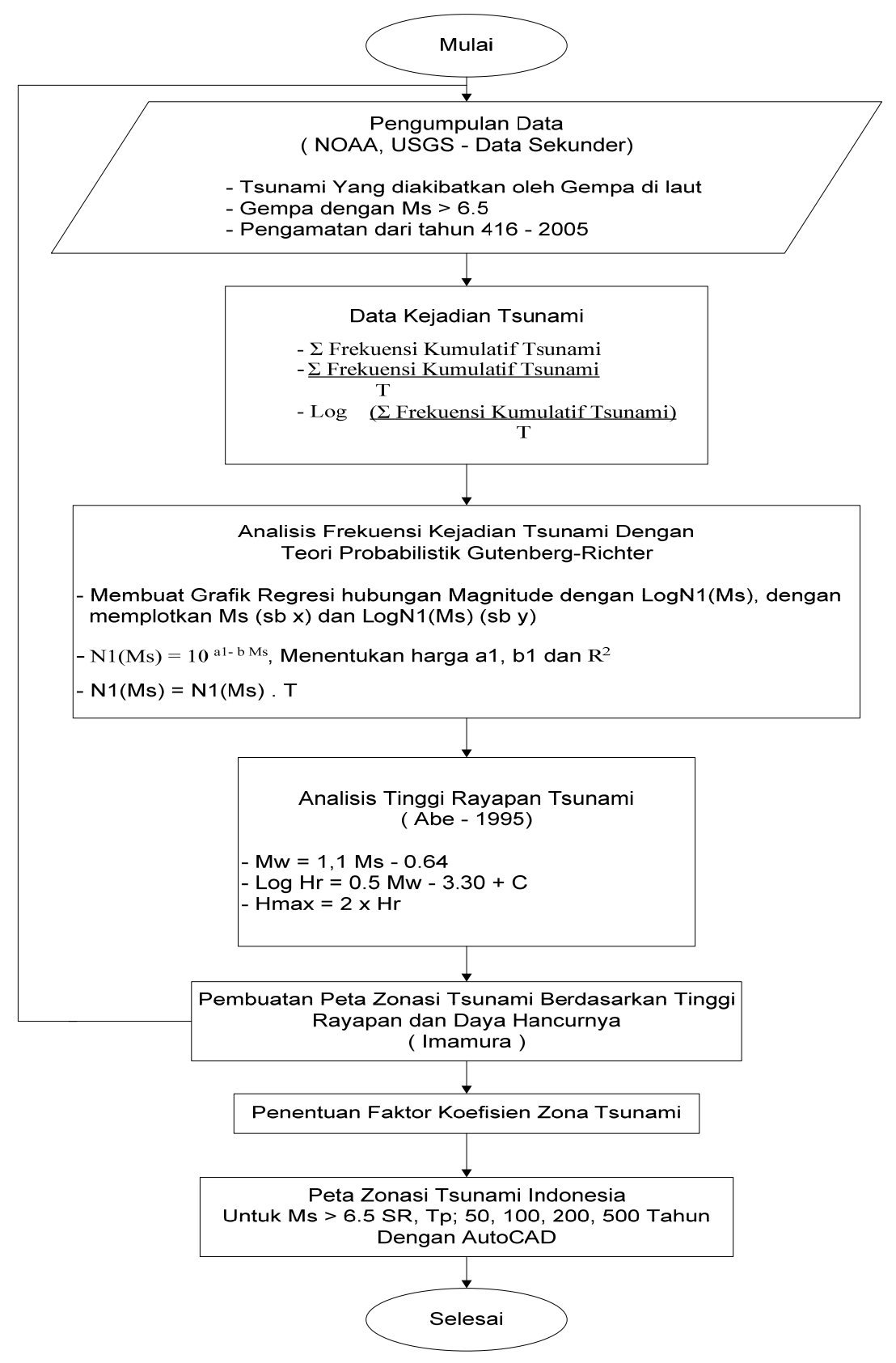

Gambar 4. Bagan Alir Pembuatan Peta Zonasi Tsunami Indonesia 


\section{PENENTUAN TINGGI RAYAPAN TSUNAMI}

Metoda menentukan tinggi rayapan tsunami dikembangkan oleh K.Abe (Abe, 1995) berdasarkan Persamaan 4.

$\log \mathrm{Hr}=0.5 \mathrm{Mw}-3.30+\mathrm{C}$

dimana, $\quad \mathrm{Hr} \quad$ : Batas tinggi tsunami disekitar pusat gempa

Mw : Magnitudo momen

C : Konstanta

Dalam perhitungan tinggi rayapan tsunami dipakai data kejadian tsunami Indonesia yang diakibatkan oleh pergeseran lempeng tektonik yang diperoleh dari NOAA dan USGS. Data-data tersebut merupakan kejadian gempa yang menyebabkan tsunami yang terjadi diseluruh wilayah Indonesia dari tahun 416 hingga 2005.

Data kejadian gempa menginformasikan waktu (tanggal, bulan dan tahun), koordinat pusat gempa, besaran gempa dalam Ms (magnitude surface) serta hanya menggunakan data yang memiliki Ms $\geq 6,5$.

Perhitungan tinggi rayapan menggunakan perioda ulang $\mathrm{T}=50,100,200,500$ tahun sebagai asumsi perioda ulang untuk gempa tektonik yang menyebabkan gelombang tsunami.

Proses analisis menggunakan teori kejadian kumulatif tahunan serta menggunakan metoda yang diciptakan K.Abe (1995). Sebagai contohnya, analisis telah dilakukan pada data gempa pantai barat Aceh dan Sumatra Utara

Tabel 2. Frekuensi Kumulatif Gempa daerah Aceh dan Sumatera Utara

\begin{tabular}{|c|c|c|c|c|c|c|c|c|c|c|}
\hline \multirow{2}{*}{$\begin{array}{c}\text { Aceh- } \\
\text { Sumatera }\end{array}$} & \multirow{2}{*}{ Thn } & \multicolumn{3}{|c|}{ Kedalaman } & \multicolumn{6}{|c|}{ Frekuensi Kumulatif Gempa Lebih Besar = } \\
\hline & & Min & Rata2 & Maks & $>6.5$ & $>7.0$ & $>7.5$ & $>8.0$ & $>8.5$ & $>9$ \\
\hline & 1754 & & & & 1.0 & & & & & \\
\hline & 1837 & & & & 1 & 1 & & & & \\
\hline & 1843 & & & & 1 & 1 & & & & \\
\hline & 1852 & & & & 1 & & & & & \\
\hline & 1861 & & & & 2 & 2 & & & & \\
\hline & 1885 & & & & 1 & & & & & \\
\hline & 1907 & & & & 1 & 1 & 1 & & & \\
\hline & 1935 & & & & 1 & 1 & 1 & & & \\
\hline & 1936 & & & & 1 & 1 & & & & \\
\hline & 1941 & & & & 1 & 1 & 1 & & & \\
\hline & 1948 & & & & 1 & & & & & \\
\hline & 1949 & & & & 1 & & & & & \\
\hline & 1955 & & & & 1 & 1 & & & & \\
\hline & 1964 & & & & 1 & 1 & & 1 & & \\
\hline & 1967 & & & & 1 & 1 & 1 & & & \\
\hline & 2002 & & & & 1 & & & & & \\
\hline
\end{tabular}




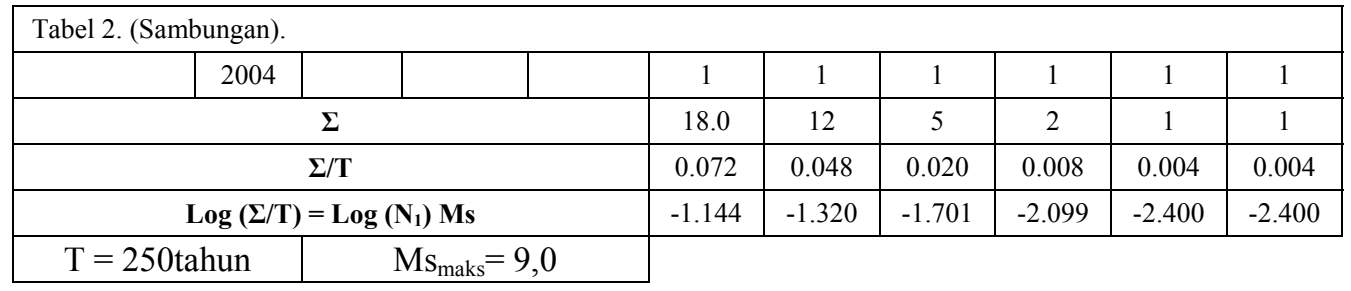

Dari hasil analisis yang dilakukan pada Tabel 2, didapat nilai-nilai Log (N1) Ms untuk setiap frekuensi kumulatif kejadian gempa yang menyebabkan tsunami. Kemudian dibuat grafik regresi hubungan antara Ms vs $\log \left(\mathrm{N}_{1}\right)$ Ms untuk mengetahui koefisien $a 1, b$ dan $\mathrm{R}^{2}$.

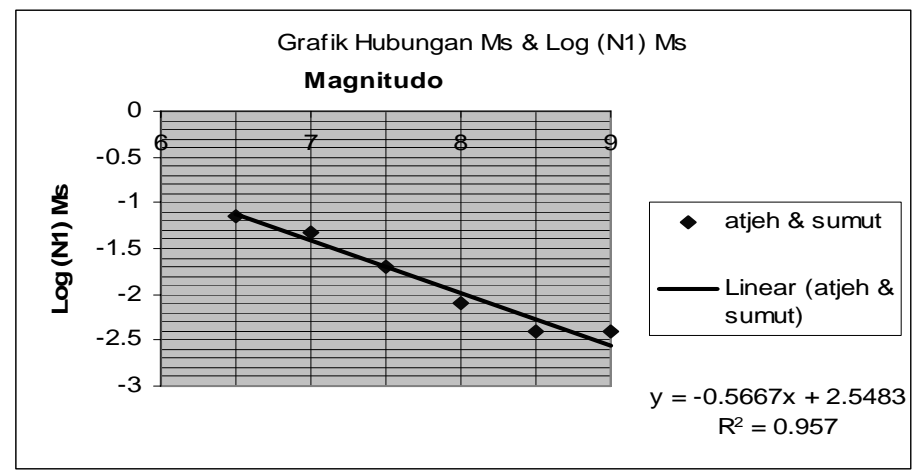

Gambar 5. Grafik Regresi Hubungan Antara Ms Dan Log $\left(\mathbf{N}_{1}\right)$ Ms

Dari Gambar 5 diatas diperoleh persamaan yaitu :

$$
y=2.5483-0.5667 x
$$

Dimana $\mathrm{a}_{1}=2.5483, \mathrm{~b}=0.5667$, dan $\mathrm{R}^{2}=0.957$

Analisis tinggi rayapan tsunami dihitung untuk perioda ulang $\mathrm{T}=50,100,200$ dan 500 tahun, dengan menggunakan persamaan (Abe) $\log \mathrm{Hr}=0.5 \mathrm{Mw}-3.30$.

Tabel 3. Hr dan Hm

\begin{tabular}{|c|c|c|c|c|}
\hline $\mathbf{T}$ & $\mathbf{M s}$ & $\mathbf{M w}$ & $\mathbf{H r}$ & $\mathbf{H m}$ \\
\hline 50 & 7.49 & 7.60 & 3.18 & 6.36 \\
\hline 100 & 8.03 & 8.19 & 6.23 & 12.45 \\
\hline 200 & 8.56 & 8.77 & 12.20 & 24.40 \\
\hline 500 & 9.26 & 9.00 & 15.85 & 31.70 \\
\hline
\end{tabular}

Dari Tabel 3 kita dapat mengetahui $\mathrm{Hr}$ dan $\mathrm{Hm}$. Hr merupakan tsunami run-up heigts, sedangkan $\mathrm{Hm}$ adalah limiting tsunami run-up heigts diperoleh dari nilai $\mathrm{Mw}=9$, yang merupakan batasan tertinggi pada proses analisis ini. Dengan menggunakan metoda ini, 
analisis dilanjutkan untuk menghitung tinggi rayapan tsunami di seluruh wilayah Indonesia yang kemudian diplot pada Peta Zona Tsunami Indonesia sesuai dengan tinggi rayapan.

\subsection{Analisis Koefisien Zona Tsunami ( $\alpha$ )}

Koefisien zona tsunami $(\alpha)$ yang ditampilkan pada peta yaitu faktor pengali untuk menentukan tinggi rayapan pada suatu zona, dengan mengalikan tinggi rayapan dasar dan koefisien zona tsunami.Tinggi rayapan dasar merupakan asumsi yang ditentukan sebagai nilai pembagi untuk menentukan nilai koefisien $\alpha$, yaitu tinggi rayapan pada suatu daerah dibagi tinggi rayapan dasar sesuai perioda ulang. Pada pambuatan peta ini, tinggi rayapan daerah Aceh dan Sumatera Utara digunakan sebagai nilai pembagi.

\section{Tabel 4. Tinggi Rayapan Dasar \&Tinggi Rayapan Dasar Maksimum} untuk setiap perioda ulang

\begin{tabular}{|c|c|}
\hline Hbr & Hbm \\
\hline 3.2 & 6.4 \\
\hline 6.3 & 12.6 \\
\hline 12.3 & 24.6 \\
\hline 16 & 32 \\
\hline
\end{tabular}

Sebagai contohnya, diambil daerah DKI Jakarta dan Lampung untuk mengetahui koefisien tinggi rayapan dasar dan koefisien rayapan dasar maksimum. Untuk Daerah DKI Jakarta dan Lampung dapat dilihat pada Tabel 5.

Tabel 5. Daerah DKI Jakarta dan Lampung

\begin{tabular}{|c|c|c|c|c|c|c|}
\hline $\mathrm{T}$ & Ms & Mw & $\mathrm{Hr}$ & $\mathrm{Zr}$ & $\mathrm{Hm}$ & $\mathrm{Zm}$ \\
\hline 50 & 6.83 & 6.87 & 1.36 & 0.42 & 2.72 & 0.42 \\
\hline 100 & 7.49 & 7.60 & 3.17 & 0.50 & 6.34 & 0.50 \\
\hline 200 & 8.16 & 8.34 & 7.38 & 0.60 & 14.77 & 0.60 \\
\hline 500 & 9.04 & 9 & 15.85 & 0.99 & 31.70 & 0.99 \\
\hline & & & & $\begin{array}{c}\Sigma / 4= \\
0.63\end{array}$ & & $\begin{array}{c}\Sigma / 4= \\
0.63\end{array}$ \\
\hline
\end{tabular}

Dimana $\mathrm{T}$ adalah asumsi perioda ulang gempa (tsunamigenic earthquake return period), $\mathrm{M}$ dan $\mathrm{Mw}$ adalah besaran gempa, $\mathrm{Hr}$ adalah tinggi rayapan tsunami, $\mathrm{Hm}$ adalah tinggi rayapan maksimum tsunami, $(\mathrm{Zr}$ dan $\mathrm{Zm})=\alpha$ adalah koefisien pengali untuk masing masing zona dan perioda ulang.

Untuk Wilayah Kepulauan Indonesia, zonasi yang dilakukan terdiri dari 4 zona yang merupakan daerah rawan terjadinya gelombang tsunami dan zona 0 dianggap mengalami distance tsunami. 
Tabel 6. Koefisien Zona Tsunami ( $\alpha$ ) Untuk Wilayah Kepulauan Indonesia

\begin{tabular}{|c|c|}
\hline Zona 0 & $0.00-0.29$ \\
\hline Zona 1 & $0.30-0.49$ \\
\hline Zona 2 & $0.50-0.69$ \\
\hline Zona 3 & $0.70-0.89$ \\
\hline Zona 4 & $0.90-1,10$ \\
\hline
\end{tabular}

Mengacu pada pembagian zona tsunami (Tabel 3), DKI Jakarta dan Lampung memiliki nilai $\Sigma \mathrm{Zr} / 4=0.63$ termasuk ke dalam zona 2 .

Hasil perhitungan tinggi rayapan tsunami untuk setiap daerah diklasifikasikan berdasarkan tinggi rayapan yang kemudian tinggi rayapan tersebut akan digunakan untuk membuat zonasi tsunami.

\subsection{Penggunaan Peta Zona Tsunami Indonesia}

Cara menggunakan Peta Zona Tsunami Indonesia yaitu dengan menentukan zona/wilayah yang akan kita amati. Sebagai contohnya diambil daerah Pantai Selatan Pulau Jawa. Untuk wilayah ini, pada peta termasuk kedalam zona 1. Untuk perioda ulang 50 tahun, proses analisisnya sebagai berikut :

$$
\begin{aligned}
\mathrm{Hr} & =\operatorname{Hbr} \times \alpha, \\
& =3.2 \times 0.4 \\
& =1.28 \mathrm{~m} . \\
\mathrm{Hm} & =\operatorname{Hbm} \times \alpha, \\
& =6.4 \times 0.4 \\
& =2.56 \mathrm{~m} .
\end{aligned}
$$

\section{KESIMPULAN}

1. Kepulauan Indonesia dibagi kedalam 5 zona, yaitu :
a. Zona 0 , dengan koefisien $\alpha=0.00-0.029$
b. Zona 1, dengan koefisien $\alpha=0.30-0.049$
c. Zona 2, dengan koefisien $\alpha=0.50-0.069$
d. Zona 3, dengan koefisien $\alpha=0.70-0.089$
e. Zona 4, dengan koefisien $\alpha=0.90-1.10$

2. Jarak episentrum gempa sangat menentukan Magnitud Surface (Ms), dimana mempengaruhi tinggi rayapan tsunami (tsunami runup heights). 
3. Daerah - daerah rawan tsunami di Indonesia, mayoritas terdapat di wilayah pantai barat Sumatera, Selatan Jawa dan Sulawesi bagian Utara Serta Barat Laut Irian Jaya, yang merupakan pengaruh dari pergerakan lempeng Eurasia, Pasifik dan Hindia Australia.

\section{DAFTAR PUSTAKA}

1. Young, K. (1975), Geology the Paradox Earth and Man, Houghton Mifflin Company, Boston.

2. Kramer, (1996), Geotechnical Earthquake Engineering.

3. Najoan, T.F. (2005), Peta Zonasi Gempa dan Tsunami Untuk Sebagai Acuan Dasar Perencanaan Pembangunan, Diskusi Mitigasi Pasca Bencana Gempa Bumi \& Tsunami Aceh, UNPAR.

4. url : http://www.NewSCIENTIST.com.

5. url : http://www.USGS.com.

6. url : http://www.WIKIPEDIA.com.

${ }^{[1]}$ Theodore F. Najoan, PUSLITBANG Sumber Daya Air

${ }^{[2]}$ Ari Budiman, Alumni Teknik Sipil Universitas Kristen Maranatha 


\section{LAMPIRAN}

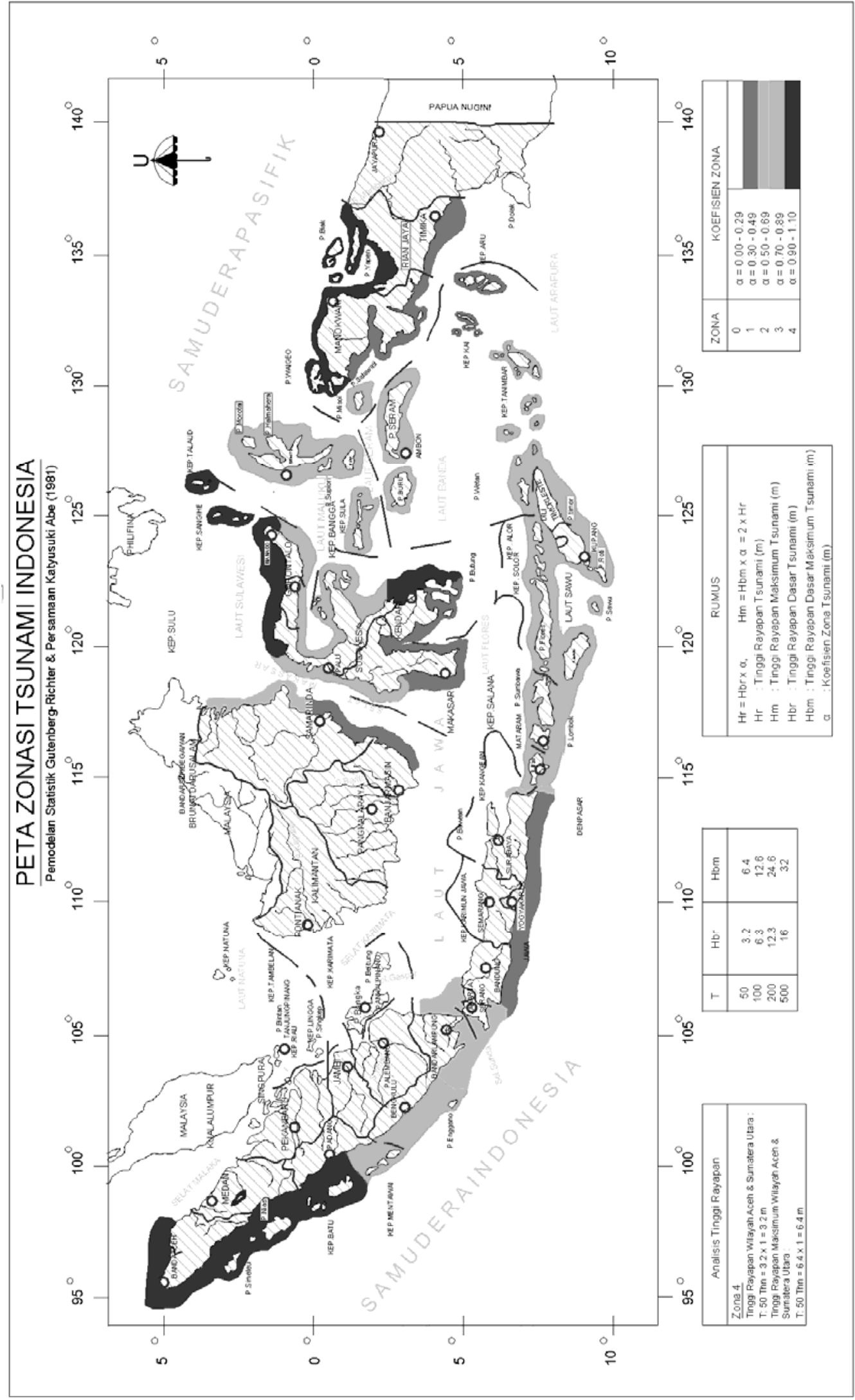

